\title{
DETERMINATION OF FANATIC CONSUMER BEHAVIOURS AT THE PERSONALITY LEVEL
}

\author{
*Aysel ERCIS \\ *F. Gorgun DEVECI \\ **Bahar TURK \\ *Atatürk University, Turkey \\ **Ondokuz Mayls University, Turkey
}

\begin{abstract}
This study aims to determine fanatic consumer behaviours according to their personalities. For this purpose, personality, fanatical tendency and fanatic behaviours have been included in the scope of this study in order to determine the fanatical tendency of the personality traits and the effect of fanatical tendency on the fanatic behaviours. As a result of the study which included the consumers aged 18 and over and living in Erzurum, it has been determined that personality dimensions including conscientiousness, neuroticism and openness to experience have effect on fanatical tendencies and fanatical tendencies on fanatic consumer behaviours.
\end{abstract}

Keywords: Personality Traits, Fanatical Tendency, Fanatic Consumer Behaviour

\section{INTRODUCTION}

Nowadays, there are many special interests in which individuals can engage during their leisure time. Sports activities, collecting, arts and crafts, TV, internet and social media are just a few of these fields. As the leisure time of the individuals' increases, the activities carried out during these time periods also gain more importance (Mackellar, 2006). Many consumers develop loyalty to sports activities/their teams, brands that satisfy a variety of personal needs, areas and other forms of consumption. The variable in question has many levels and it is called 'fanaticism' in general terms (Redden and Steiner, 2000; Steiner, 2004). Fanaticism is becoming increasingly common in all areas of consumption today (Chung et al., 2017) and behaviours of fanatic individuals have gained importance in the modern world (Smith et al. 2007). Personality refers to individual's unique psychological and physical characteristics. Fanatic individuals and other individuals, who are similar interests, have similar personality traits (Thorne, 2003). Within the scope of the study, these personality traits and the influence on fanatic tendencies were discussed. From this point of view; "Determination of Fanatic Consumers Behaviours in Personality Level" is aimed and variables of personality, fanatical tendency and fanatic consumer behaviour are discussed in the study.

\section{LITERATURE REVIEW Personality Traits}

Personality values are assessed according to psychographic variables such as lifestyle and attitudes (Fraj and Martinez, 2006). Personality is defined as the unique organization of an individual's mental world, and according to Hung et al. (2015), it explains behaviour or reactions of the individual under similar conditions.

Personality; is a consistent and structured relationship established by the individual with his/her inner and outer environment (Banarjee, 2016), distinguishing him/her from other individuals. It is also defined as the sum of the characteristics that distinguish the person from other people and direct him/her to a different mode of action in different situations (Koç, 2013). Although there are many different theories about the measurement of personality traits, the approach often used in recent years is known as the FiveFactor Personality Model, "Big Five" or "Five-Factor Model". Five Factor Personality Model is a hierarchical model that suggests that most individual differences in personality can be divided into five broad areas that are experimentally derived (Gosling et al., 2003). In marketing studies, "Five Factor Personality Structure" is used to determine the effect of personalities of the consumers on perception, preferences and behaviour (Mulyanegara et al., 2009; Banerjee, 2016). According to theory, there are five 
basic dimensions of personality and the dimensions are as follows; Agreeableness, Extroversion, Neuroticism, Conscientiousness, Openness to Experience. Each dimension contains different personality traits and characteristics. These dimensions include (Goldberg; 1990; Goldberg, 1992; McCrae and John, 1992; Rammstedt and John, 2007; Butt and Phillips, 2008; Soto and John, 2009; Tang et al., 2016; Leong et al., 2017);

Agreeableness: The individuals in this dimension called the dimension of conformity to the social norms are agreeable so it is possible that the individuals involved in this dimension develop and maintain good relations with others (Mishra and Vaithianathan, 2015). The individuals for whom the agreeableness dimension is relevant display a human nature (John and Srivastava, 1999; Quintelier, 2014) and behave warmly and sincerely in social interactions (Migliore, 2011; Banerjee, 2016).

Extraversion: Individuals for whom this dimension is relevant have a more energetic approach to the world than other individuals and socialize by communicating with more people (John and Srivastava, 1999; Quintelier, 2014). Extraversion measures the amount and intensity of interpersonal interaction, activity level and happiness capacity (Mulyanegara et al., 2009; Ross et al., 2009; Islam et al., 2017).

Neuroticism: Individuals in the dimension called neuroticism (Migliore, 2011; Mishra and Vaithianathan, 2015) tend to feel more anxiety, tension and sadness than the other individuals. Stable individuals are calm, relaxed and trustworthy (John and Srivastava, 1999; Jani and Han, 2014; Quintelier, 2014; Banarjee, 2016).

Conscientiousness: The dimension of conscientiousness is the dimension related to following norms and rules. Individuals in this dimension make careful decisions, behave according their decisions and organized (Soto and John, 2009; Lin, 2010; Lin and Worthley, 2012; Jani and Han, 2014; Hsiao, 2017).

Openness to experience: This dimension showing the openness, innovation, aesthetics, and interest in new ideas is the stage in which personality is associated with being open to new ideas and flexibility (Banarjee, 2016). Individuals in this dimension are curious about new experiences and products, are able to adapt to new products/brands faster, and are able to take part in the innovative group and are researchers (Ross et al., 2009 Lin, 2010; Mishra and Vaithianathan, 2015).

\section{Fanatical Tendency}

Chung et al. (2008) defines fanaticism as an emotionally-charged phenomenon and a unique form of loyalty characterized by strong-intense commitment, passion, emotional attachment, enthusiasm, and participation levels. Besides this definition, Thorne and Bruner (2006), Pichler and Hemetsberger (2007) explained fanaticism as the development of extreme opinions and feelings towards a brand, product, person (e.g. celebrity), television show, or other consumption activities. Thorne (2011) has clarified fanaticism and related concepts with his research. According to this;

Fan: A person who is constantly interested in subjects such as sports, sports teams, TV, music, etc. Fanaticism: It is an upper level of being a fan and its intensity differs according to the individuals. Fandom: A fandom is a concept that expresses a subculture of people with similar interest/interests. Dilettante: This group are interested in certain area(s), they have no motivation to increase the level of such interest. Dedicated: Individuals organize their activities according to these activities, collects objects related to such area(s), communicate with the other who have the same interest and they attend meetings and forums. Devoted: At this level, fans organize their plans, programs and lifestyles depending on their interest area(s) in order to keep close track of such area(s).

For marketing, fanatic consumers are following and support your favourite product, brand, or consumption activity or experience (Chung et al., 2017). Fans are very enthusiastic, creative and committed to buy the products/brands toward their interest area/areas. Therefore, fans are valuable and attractive consumer groups for marketers and businesses. (Redden and Steiner, 2000; Chung et al, 2009). The attitudes of the fans are very stable, but they also have a tendency to resist the messages sent by rival brands and to stick to the brands/products they use. Through fanaticism, consumers create an identity in terms of products /brands by acting like they act in their interpersonal interactions. At this point, desire and emotion are the basic elements that direct this relationship (Thorne and Bruner, 2006; Chung et al., 2008; Seregina, 2011). But in addition to these positive traits, fanatic individuals are called extreme, extravagant, and intolerant. According to fanatic individuals, their ideas are correct ones. In addition to this, the literature on the behaviour of fanatic consumers generally focuses on the behaviour of fans expressing themselves. Studies have been done to determine the characteristics of fans through obsessive 
or compulsive behaviour. At the heart of fanatic consumers lies an emotion-oriented attitude (Redden and Steiner, 2000; Mackellar, 2006; Smith et al.2007; Chung et al., 2008; Seregina, 2011). In the light of this information, it has been seen that the personality traits of fanatic individuals are at the forefront. So, it was thought that personality traits influenced fanatic tendencies and $\mathrm{H} 1$ hypothesis has been developed.

\section{H1: Personality traits have an effect on fanatical tendencies.}

\section{Fanatic Consumer Behaviour}

Research on fanatic consumer behaviours date back to 1986. This is because, fanatic consumer behaviour involves "commitment", "collecting", "compulsive consumption and addiction" (Chung et al, 2017). Fanatic individuals have more extreme behaviours than other individuals. Two features come to the forefront regarding fanatic individuals. The first is intensity; the second is value attitude (Mackellar, 2006).

The most prominent personality trait of fanatic individuals is the intensity. In other words, fanatic individuals have a tendency to live more intensely in their lives, feelings, thoughts, that is, in every aspect of their life in general. In addition to the intensity; passion, effort, enthusiasm and commitment are among the other personality traits. In fact, personality traits emerge in physical mobility and emotions (Holbrook, 1987; Redden and Steiner, 2000; Steiner, 2004; Smith, 2007; Mackellar, 2008).

Value attitude is related to the individual's self. The intensity and willingness of fanatic individuals reveal the value structures they have. In line with this intensity and willingness, a fanatical individual may prefer a product/object that he/she is a fan of rather than meeting daily needs (Mackellar, 2006; Mackellar, 2008). In this direction, it seems that fanaticism has a characteristic and behaviours. Below are the characteristics of the fanatical individuals determined by the results of the studies by Thorne and Bruner (2006). According to researcher's fanaticism have four different characteristics. These are (Thorne and Bruner, 2006);

Internal Commitment: Fans spend their time, energy and resources in a specific area of interest. They enjoy investing in their area of interest. They show more commitment to their area of interest than those who do not demonstrate fan behaviour, and the transfer of these commitments is more. According to their commitment level to there are of interest, they are more willing to make changes in their lives. This becomes an emotional cycle with an increasing desire to participate in activities related to the area that the fan is interested in. In fanaticism, besides strong emotional bonding, there are feelings of love, closeness and self-sacrifice

Desire for External Commitment: The fans are motivated to show their level of interest in an area with specific behaviours. They may prefer to read newspapers, magazines, etc., to attend presentations or participate in events, follow up on the internet/social media, or attend conferences related to their area of interest.

Desire to Win: Fans turn to consumption to express their strong commitment and make similar consumptions as other individuals with similar interests. Fans buy products related to the area they are interested in because they enjoy having that object, not because it is needed. Because having that product makes them feel closer to the area of interest and this reflects the self-perception of fans.

Desire for Social Interaction: With the development of technology, fans have started to use social media to interact with individuals who have similar interests. For this reason, they also communicate in electronic environment besides meetings and organizations. For fanatical individuals, the interaction that they have with group memberships, groups that they are members of or want to be are very important (Thorne and Bruner, 2006; Chung et al., 2008; Seregina, 2011). In addition to this, Mackellar (2006) explains fanatical consumer behaviour in three dimensions. These dimensions;

Fanatics as Consumers; fanatic individuals are often classifying in terms of extreme personality traits in consumer behaviour. Besides this, self-image is very important factor for fanatic consumers. Consumers want to change or enhance their self-image by way of their consumption. Besides these characteristics, fanatic consumer is having commitment, involvement towards interest area/areas (Mackellar, 2006).

Leisure Fanatics; Mackellar (2006) argues that the consumption of leisure time is the same as the consumption of a product. At this point, the involvement and commitment of fanatic consumers is associated with leisure time consumption. Fanatic individuals socialize with have similar interests area/areas people. Also spends time and energy in the decision-making process. In other words, fanatic 
individuals make their interests the center of their lives and this interest and behaviour is constantly on going.

Fanatics as Touristic; fanatic individuals tend to travel which is why they are interested in pursuing their interests. Fanatic individuals, especially those who are interested in special interest tourism, plan their trips in the direction of leisure time and travels (depending on interest area/areas) with their own equipment. According to fanatic consumers, their travel as a way of gaining experience for their interests (Mackellar, 2006). So, they do not have a standard route. H2 hypothesis has been developed in the light of information given.

\section{H2: Fanatical Tendency has an effect on Fanatic Consumer Behaviours.}

\section{METHODOLOGY}

\section{Purpose, Scope and Limitations of the Study}

In the study, it is aimed to reveal the fanatical tendencies of the personality traits of the consumers, that is to say the effect of the fanatical tendencies on the fanatic consumer behaviour. The consumers aged 18 and over living in Erzurum have been included in the study. The study has not focused on any area, product group or brand. Therefore, the results cannot be generalized for a single area and Turkey.

\section{Research Model}

Research model is shown in Figure 1.

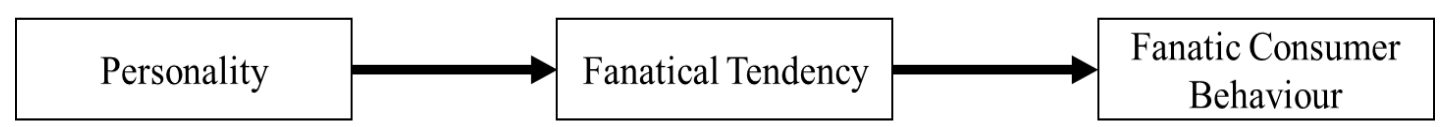

Figure 1. Research Model

\section{Sampling Process}

The population of the study is composed of consumers who are 18 years or older and living in Erzurum. In the scope of the study, convenience sampling method that is one of the non-randomized sampling methods has been preferred. 300 questionnaires were applied and 225 questionnaires were evaluated after the elimination of false and incomplete questionnaires.

\section{Data Collection Method and Tool}

The questions in the questionnaire consist of five different groups. The first group consists of questions directed to determine which area/areas the respondents are interested in and to determine the level of interest in the area/areas of interest, and to show which area/areas they follow. The questions in the second group were directed to determine the personality traits of the respondents. The scale developed by Goldberg (1990) was used to determine the personality traits of the participants. In the third group, the fanaticism tendencies of the participants were sought be determined on the basis of the statement of "fanatic consumption in terms of thoughts, behaviours and targets" in the study of Redden and Steiner (2000). Attempts were made to reveal fanatic behaviour of the participants through the questions in the fourth group. For this purpose, the expressions used in the work of Mackellar (2006) were employed. In the last part of the questionnaire, questions about the demographic characteristics of the respondents were addressed. After the scales were translated, a sampling study of 20 persons was carried out and the questionnaire was given the final form. Respondents' personality traits and fanaticism tendencies were measured with interval scale $(1=$ never, $5=$ frequently $)$ and fanatic behaviour was measured with a 5point Likert scale $(1=$ strongly disagree, $5=$ strongly agree). Data were analysed using SPSS 20.0, AMOS statistical program. Descriptive Statistics, Confirmatory Factor Analysis and Structural Equation Modelling were used in the analysis of the data.

\section{DATA ANALYSES Demographic Characteristics}

The majority of respondents are 26-33 years of age, have university level education, and an income of $1000 \mathrm{TL}$ or less. 
Journal of Global Strategic Management | V. 12 | N. 1 | 2018-June | isma.info | 081-092 | DOI: 10.20460/JGSM.2018.263

\section{Determination of the Interest Areas of the Respondents}

Respondents were asked their interest areas at first. The distribution of interest areas frequency is presented in Table 1.

Table 1. Interest Areas of the Respondents

\begin{tabular}{lcc}
\hline Interests & Frequency (f) & Percentage (\%) \\
\hline Sports Branches & 173 & 76,9 \\
Swimming/Diving & 58 & 25,8 \\
Travelling & 38 & 16,9 \\
Gourmet & 39 & 17,3 \\
Photography & 40 & 17,8 \\
Nature sports & 27 & 12,0 \\
Shopping & 105 & 46,7 \\
Collecting & 33 & 14,7 \\
Social Media Follower & 35 & 15,6 \\
Other & 9 & 4,0 \\
\hline
\end{tabular}

As seen in Table 1, Sports fields (76,9\%) and Shopping (46,7\%) are the most important areas of interest of the respondents compared to others.

\section{Determination of the Ways the Respondents Use to Follow Their Interest Areas}

Respondents were questioned about the ways they used to follow their interest areas. The distribution of follow interest areas frequency results is shown in Table 2.

Table 2. The Ways the Respondents Use to Follow Their Interest Areas

\begin{tabular}{lcc}
\hline Following of Interest Areas & Frequency (f) & Percentage (\%) \\
\hline Place of Interest Area (Stadium etc.) & 140 & 62,2 \\
Broadcast Live on the TV/Radio/Internet & 101 & 44,9 \\
Printed Media (Newspaper, Journal etc.) & 115 & 51,1 \\
Other & 37 & 16,4 \\
\hline
\end{tabular}

According to Table 2, the respondents are following their interest from the Place of Interest Areas $(62.2 \%)$ and from the printed media such as Newspaper (51.1\%).

\section{Determination of the Respondents' Level of Interest}

Respondents were questioned to find out their level of interest. The distribution of level of interest frequency is presented in Table 3.

Table 3. Respondents' Level of Interest

\begin{tabular}{lcc}
\hline Level of Interest & Frequency (f) & Percentage (\%) \\
\hline Dilettante & 16 & 7,1 \\
Devoted & 41 & 18,2 \\
Dedicated & 57 & 25,3 \\
Fan & 83 & 36,9 \\
Fandom & 28 & 12,4 \\
Total & $\mathbf{2 2 5}$ & $\mathbf{1 0 0}$ \\
\hline
\end{tabular}

As seen in Table 3, respondents regard themselves as "Fan" (36.9\%) of the area they are interested in.

\section{Confirmatory Factor Analysis Results on Research Variables}

A confirmatory factor analysis was used for testing whether the personality dimensions, fanatical tendency and fanatic consumer behaviour scales used in the study were consistent with the study sample. 

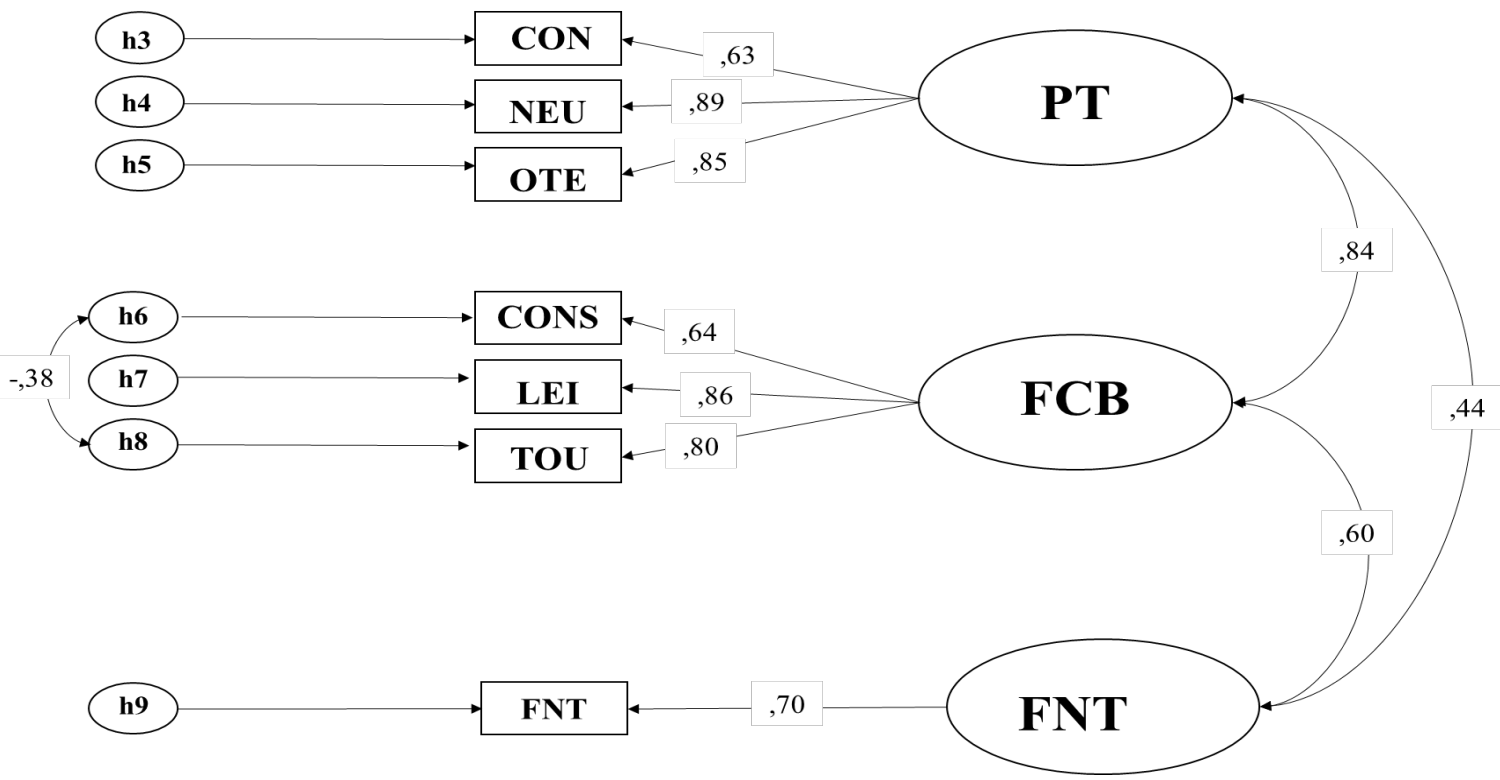

Figure 2. Confirmatory Factor Analysis

Key: $\mathrm{PT}=$ Personality Traits, $\mathrm{CON}=$ Conscientiousness, $\mathrm{NEU}=$ Neuroticism, $\mathrm{OTE}=$ Openness to experience, $\mathrm{FCB}=$ Fanatic Consumer Behaviour, $\mathrm{CONS}=$ Consumer, $\mathrm{LEI}=$ Leisure, $\mathrm{TOU}=$ Tourism, FNT $=$ Fanatical Tendency

Table 4. Fit index values for Confirmatory Factor Analysis

\begin{tabular}{lcc}
\hline Index & Model Values & Fit Index Value \\
\hline Chi-Square $\left(X^{2}\right)$ & 29,744 & \\
df & 11 & \\
$\left(X^{2}\right) / d f$ & 2,704 & $1-5$ \\
-value & 0,000 & \\
RMSEA & 0,007 & $0,05 \leq \mathrm{RMSEA} \leq 0,10$ \\
RMR & 0,014 & $0,05 \leq \mathrm{RMR} \leq 0,08$ \\
AGFI & 0,915 & $0,85 \leq \mathrm{AGFI} \leq 0,90$ \\
NFI & 0,951 & $0,90 \leq \mathrm{NFI} \leq 0,95$ \\
CFI & 0,975 & $0,95 \leq \mathrm{CFI} \leq 0,97$ \\
GFI & 0,967 & $0,90 \leq \mathrm{GFI} \leq 0,95$ \\
\hline
\end{tabular}

As seen in the table, the $(\mathrm{X} 2) / \mathrm{df}$ ratio is found to be 2.70 below the reference value. RMSEA is at acceptable level of 0.07. NFI, CFI, GFI and AGFI values are also at acceptable compliance levels.

Table 5. DFA Results Regarding Variables

\begin{tabular}{ccccc}
\hline Statistically Significant Ways & $(\mathrm{t})$ Values & Standardized Coefficients & Error Variances & $\mathrm{R}^{2}$ \\
\hline Personality $\rightarrow$ Openness to experience & & 0,855 & 0,731 \\
Personality $\rightarrow$ Neuroticism & 15,687 & 0,889 & 0,067 & 0,790 \\
Personality $\rightarrow$ Conscientiousness & 10,198 & 0,635 & 0,058 & 0,403 \\
Fanatic Consumer Behaviour $\rightarrow$ Tourism & & 0,803 & 0,644 \\
Fanatic Consumer Behaviour $\rightarrow$ Leisure & & 0,857 & 0,096 & 0,734 \\
Fanatic Consumer Behaviour $\rightarrow$ Consumer & 13,184 & 0,644 & 0,415 \\
Fanatic $\rightarrow$ Fanatic & 8,398 & 0,705 & 0,497 \\
\hline
\end{tabular}

When the results of the confirmatory factor analysis were examined, it was seen that among the sub dimensions of the personality variable, the conscientiousness, neuroticism and openness to experience produced statistically significant results and they were included in the model. 


\section{Testing the Research Model}

It was intended to study the influence of personality on fanatical tendency and the influence of fanatical tendency on fanatic consumer behaviour. The results are presented below.

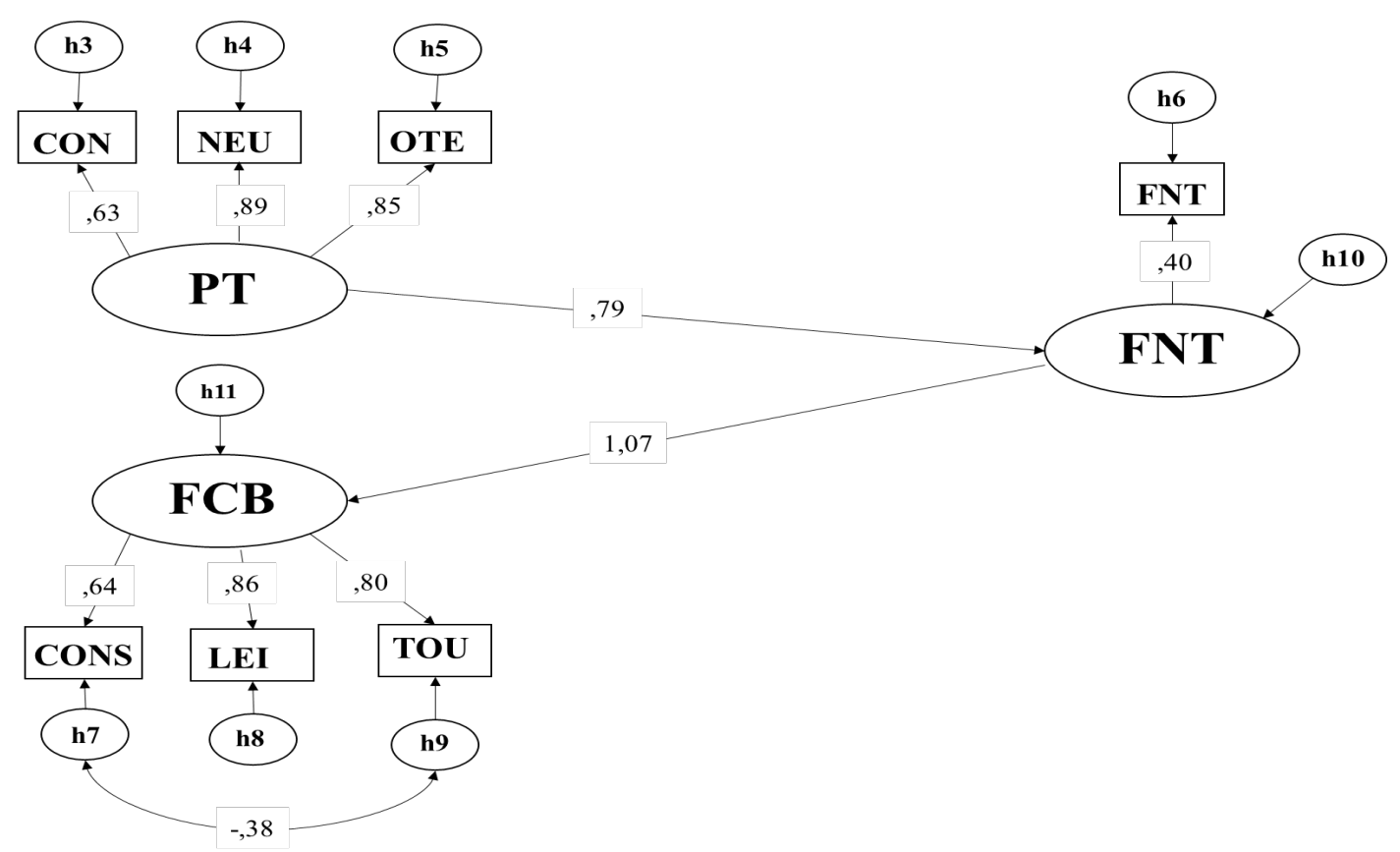

Figure 3. Research Model Testing

Table 6. Fit Index Values for Structural Model

\begin{tabular}{lcc}
\hline Index & Structural Model Values & Fit Index Value \\
\hline Chi-Square $\left(\mathrm{X}^{2}\right)$ & 29,744 & \\
$\mathrm{df}$ & 11 & \\
$\left(\mathrm{X}^{2}\right) / \mathrm{df}$ & 2,704 & $1-5$ \\
$\mathrm{p}$-value & 0,000 & \\
RMSEA & 0,007 & $0,05 \leq \mathrm{RMSEA} \leq 0,10$ \\
RMR & 0,014 & $0,05 \leq \mathrm{RMR} \leq 0,08$ \\
AGFI & 0,915 & $0,85 \leq \mathrm{AGFI} \leq 0,90$ \\
NFI & 0,961 & $0,90 \leq \mathrm{NFI} \leq 0,95$ \\
CFI & 0,975 & $0,95 \leq \mathrm{CFI} \leq 0,97$ \\
GFI & 0,967 & $0,90 \leq \mathrm{GFI} \leq 0,95$ \\
\hline
\end{tabular}

As seen in the table, the $(\mathrm{X} 2) / \mathrm{df}$ ratio is found to be 2.70 below the reference value. RMSEA is at acceptable level of 0.07 . NFI, CFI, GFI and AGFI values are also at acceptable compliance levels. 
Table 7. DFA Results for Structural Model

\begin{tabular}{lcccc}
\hline Statistically Significant Ways & $\begin{array}{c}(\mathrm{t}) \\
\text { Values }\end{array}$ & $\begin{array}{c}\text { Standardized } \\
\text { Coefficients }\end{array}$ & Error Variances & $\mathrm{R}^{2}$ \\
\hline Personality $\rightarrow$ Fanatical Tendency & 4,299 & 0,786 & 0,077 & 0,617 \\
Fanatical Tendency $\rightarrow \quad$ Fanatic Consumer & 4,679 & 1,072 & 0,765 & 1,148 \\
Behaviour & & & & \\
Personality $\rightarrow$ Conscientiousness & & 0,635 & & 0,403 \\
Personality $\rightarrow$ Neuroticism & 10,392 & 0,889 & 0,171 & 0,790 \\
Personality $\rightarrow$ Openness to experience & 10,198 & 0,855 & 0,167 & 0,731 \\
Fanatic Consumer Behaviour $\rightarrow$ Tourism & & 0,803 & & 0,644 \\
Fanatic Consumer Behaviour $\rightarrow$ Leisure & 13,184 & 0,857 & 0,096 & 0,734 \\
Fanatic Consumer Behaviour $\rightarrow$ Consumer & 8,398 & 0,644 & 0,115 & 0,415 \\
Fanatic $\rightarrow$ Fanatic & & 0,400 & & 0,601 \\
\hline
\end{tabular}

In the structural equation analysis carried out by taking into account the confirmatory factor analysis results, it has been determined that the combined dimensions are reliable. According to the results of Structural Equation Analysis; H1 and H2 hypothesis have been accepted.

\section{CONCLUSION AND SUGGESTIONS}

In the study conducted for 'Determination of Fanatic Consumer Behaviours at Personality Level; the majority of respondents are 26-33 years of age, have university level education, and an income of 1000 TL or less. Respondents are most interested in sports fields (76.9\%) and shopping (46.7\%), and they mostly refer to themselves as "Fan" $(36.9 \%)$ of their areas of interest. Respondents follow their interests from the place they are performed $(62.2 \%)$ and from printed media such as newspapers $(51.1 \%)$. Confirmatory factor analysis was applied to the scales used in the study before the research model was tested. Finally, an analysis of the research model was made using Structural Equation Modelling (SEM). It has been determined that the research model is significant according to Structural Equation Modelling. According to the results, it has been determined that personality dimensions including conscientiousness, neuroticism and openness to experience have effect on fanatical tendencies and fanatical tendencies on consumer, leisure and touristic fanatic consumer behaviours. Based on the results obtained, the following suggestions have been developed;

Fanatic individuals are individuals who have emotional intensity. This result is further supported by the fact that the personality dimension of neuroticism has a significant effect according to the analysis made within the scope of the study. At this point it is important that the emotional messages directed to the area/ areas that the fanatic individuals are interested in are transmitted and their emotions are addressed. Businesses and/or brands may move a step further in competitive terms by giving the impression that have similar interests and share similar emotions with these individuals and may keep fanatical individuals as long as their rivals do not offer more. So the concept of emotional branding may become prominent. Apart from this, following the norms and group consciousness have a strong influence in fanatic individuals. These individuals have tendency to follow the groups with which they share the same area/areas of interest and their norms and rules. In line with this result, it may be true to approach the individuals who follow the same area/areas of interest with a product/brand idea that is not consumed by other consumers, produced only for them, and consumed or purchased by individuals with similar interests. Opinion leaders are a reference group that is important at this point. Fans can be reached by benefiting the power of the opinion leaders to influence the individual.

Fans buy products related to the area they are interested in because they enjoy having that object, not because it is needed. Because having that product makes them feel closer to the area of interest, and this reflects the self-perception of fans and the importance they attach to the group consciousness. So, for fanatics not only having that product but also demanding and sharing that product is very important. At this point, organizations related to the interest areas of the fans can be held, team spirit can be created and fan groups can be formed to bring them together and enable them to interact. Thus, the fans both act within the group consciousness and form their self-perception.

Another result of study is that fanatic individuals are subjects open to experience. That is why fanatical consumer groups are part of the innovative group and are the first to buy and sell products/brands related 
to the area/areas they are interested in. Fanatic individuals as a part of the innovative group accordingly attract the attention of businesses. Businesses may market their products/brands at high prices to this group of consumers with the emphasis on quality and gain prestige on the basis of this consumer group, because they are the first to buy and try the brands/products presented to the market by the business as well as they act with the idea that "this product must be owned only by me". The tendencies of the individuals with fanatical tendencies turn into behaviour as a result of the businesses and marketing efforts they have carried out. There are different levels of fanaticism. Purchasing tendencies of the individuals also differs according to the importance and level of interest they attach to their area/areas of interest. The growing mass of fanatic individuals is important in terms of creating a subculture that contains them and sustaining this culture. The primary goal of businesses at this point must be to attract fanatic individuals to themselves. Because fans at dilettante level follow TV programs, newspapers, magazines, etc. related to their area of interest. Messages can be given using the mentioned media channels. It has been shown the fans at the dedicated level set their lifestyles based on the area they are interested in, that they follow their interests through all channels, collect and accumulate the products, and participate in organizations of their interests. At this point, the product launches that bring these individuals together can be organized and the product/brand can be introduced to them first and they can feel privileged. At the same time, they can communicate with each other through social media applications and the sponsorship activities of the company or its related brand can be realized through this point. Fans at the devoted level go through major changes in their lifestyle in the direction of their interest. They spare a large part of their free time to their interests. Loyalty programs can be developed in line with the commitment levels for all the groups mentioned at this point, and committed fanatic consumer groups can be created by engaging in viral and relational marketing efforts.

When considering fanatic consumer behaviour from the perspective of businesses; xxplicit market segments can be revealed from the viewpoint of fanatic consumer. New strategic marketing mixes can be determined according to the lifestyles and personalities of these market segments. Fanatic consumers, because of the features, are creating explicit and loyal market. Therefore, it can be considered as a research group in determining future market strategies by businesses. Therefore, it is an important market that needs to be examined very carefully.

\section{RECOMMENDATIONS FOR FUTURE STUDIES}

In future studies on fanaticism and fanatic trends, it is possible to examine whether there are distinct market segments and make market segmentation by taking into account the fanaticism trends of consumers. In addition to market segmentation, it is possible to conduct studies on the presence/absence of advisory groups by examining fanatic individuals in terms of "Innovative" - "Opinion Leader". In this way, market definition can be made in terms of the enterprises, and each segment can be entered into with the appropriate product/brand/price/ feature offers. In addition, the use of social media by fanatic individuals can be examined. Social media has become an increasingly important medium in recent years. For this reason, the contributions made by fanatic individuals on social media can be examined and product and brand offers can be considered in terms of social media relations. In addition to opinion leaders, social media has gained importance in recent years in the communication and interaction between individuals. Through the channels such as social media, twitter, Instagram etc., it is possible to inform the fans about the product/brand for their interests and if it is applicable, the product/brand can be sold through the same channels (via Instagram, Twitter). 


\section{Journal of Global Strategic Management | V. 12 | N. 1 | 2018-June | isma.info | 081-092 | DOI: 10.20460/JGSM.2018.263 REFERENCES}

Banerjee, S., (2016). "Influence of Consumer Personality, Brand Personality, and Corporate Personality on Brand Preference". Asia Pacific Journal of Marketing and Logistics, Vol.28, No.2, pp.198-216.

Butt, S., Phillips, J.G. (2008). "Personality and Self-Reported Mobile Phone Use". Computers in Human Behaviour, Vol.24, No.2, pp.346-360.

Chung, E., Beverland, M.B., Farrelly, F., Quester, P. (2008). "Exploring Consumer Fanaticism: Extraordinary Devotion in the Consumption Context". Advances in Consumer Research, Vol.35, pp.33340.

Chung, E., Beverland, M.B., Farrelly, F., Quester, P. (2009). "The Dark Side of Consumer Fanaticism”. ANZMAC, Melbourne, Australia.

Chung, E., Farrelly, F., Beverland, M.B., Karpen, I.O. (2017). "Loyalty or Liability: Resolving The Consumer Fanaticism Paradox". Marketing Theory, pp.1-28.

Fraj, E., Martinez, E. (2006). "Influence of Personality on Ecological Consumer Behaviour”. Journal of Consumer Behaviour, Vol.5, pp.167-181.

Goldberg, L. R. (1990). An alternative “"Description of Personality”: The Big-Five factor structure”. Journal of Personality and Social Psychology, Vol.59, pp.1216-1229.

Goldberg, L. R. (1992). “The Development of Markers for the Big Five Factor Structure”. Psychological Assessment, Vol.4, pp.26-42.

Gosling, S. D., Rentfrow, P. J., Swann, W. B., Jr. (2003). "A Very Brief Measure of the Big-Five Personality Domains". Journal of Research in Personality, Vol.37, pp.504-528.

Holbrook, M.B. (1987). "An Audiovisual Inventory of Some Fanatic Consumer Behaviour: The 25-Cent Tour of A Jazz Collector's Home”. Advances in Consumer Research, pp.144-149

Hsiao, K.L. (2017). "Compulsive Mobile Application Usage and Technostress: The Role of Personality Traits”, Online Information Review, Vol.41, No.2, pp.272-295.

Hung, W.H., Chen, K., Lin, C.P. (2015). "Does the Proactive Personality Mitigate the Adverse Effect of Technostress on Productivity in the Mobile Environment?" Telematics and Informatics, Vol.32, No.1, pp.143-157.

Islam, J.U., Rahman,Z., Hollebeek, L.D. (2017). "Personality Factors as Predictors of Online Consumer Engagement: An Empirical Investigation”. Marketing Intelligence \& Planning, Vol.35, No.4, pp.510-528.

Jani, D., Han, H. (2014). "Personality, Satisfaction, Image, Ambience, and Loyalty: Testing Their Relationships in the Hotel Industry”. International Journal of Hospitality Management,Vol. 37, pp.11-20.

John, O.P., Srivastava, S. (1999), "The Big Five Trait Taxonomy: History, Measurement, and Theoretical Perspectives", Handbook of Personality: Theory and Research, Vol.2, No.1, pp.102-138.

Koç, E. (2013). "Tüketici Davranışı ve Pazarlama Stratejileri, Global ve Yerel Yaklaşım”. Seçkin Yayınc1lık: Ankara.

Leong, L.Y., Jaafar, N.I., Sulaiman, A. (2017). "Understanding Impulse Purchase In Facebook Commerce: Does Big Five Matter?”, Internet Research, Vol.27, No.4, pp.786-818.

Lin, I.Y., Worthley, R. (2012). "Servicescape Moderation on Personality Traits, Emotions, Satisfaction and Behaviours". International Journal of Hospitality Management, Vol.31, pp.31-42.

Lin, L.Y. (2010). "The Relationship of Consumer Personality Trait, Brand Personality and Brand Loyalty: An Empirical Study of Toys and Video Games Buyers”. Journal of Product \& Brand Management, Vol.19, No.1, pp.4-17.

Mackellar, J. (2006). "Fanatics, Fans or Just Good Fun? Travel Behaviours and Motivations of The Fanatic". Journal of Vacation Marketing, Vol.12, No.3, pp.195-217.

Mackellar, J. (2008). "Dabblers, Fans and Fanatics: Exploring Behavioural Segmentation at A SpecialInterest Event". Journal of Vacation Marketing, Vol.15, No.1, pp.5-24. 
McCrae, R.R., John, O.P. (1992). "An Introduction to the Five-Factor Model and Its Applications". Journal of Personality, Vol.60, No.2, pp. 175-215.

Migliore, L.A. (2011). "Relation between Big Five Personality Traits and Hofstede's Cultural Dimensions: Samples from the USA and India", Cross Cultural Management: An International Journal, Vol.18, No.1, pp.38-54.

Mishra, V., Vaithianathan, S. (2015). "Customer Personality and Relationship Satisfaction: Empirical Evidence From Indian Banking Sector”, International Journal of Bank Marketing, Vol.33, No.2, pp.122142.

Mulyanegara, R.C., Tsarenko, Y., Anderson, A. (2009). "The Big Five And Brand Personality: Investigating The Impact Of Consumer Personality On Preferences Towards Particular Brand Personality". Journal of Brand Management, Vol.16, No.4, pp.234-247.

Pichler, E.A., Hemetsberger, A. (2007). "Hopelessly Devoted to You" Towards An Extended Conceptualization of Consumer Devotion". Advances in Consumer Research, Vol.34, pp.194-197.

Quintelier, E. (2014). "The Influence of the Big 5 Personality Traits on Young People's Political Consumer Behaviour", Young Consumers, Vol.15, No.4, pp.342-352

Rammstedt, B., John, O.P. (2007). "Measuring personality in one minute or less: A 10-item short version of the Big Five Inventory in English and German". Journal of Research in Personality, Vol.41, pp.203212

Redden, J., Steiner, C.J. (2000). "Fanatical Consumers: towards a Framework for Research". Journal of Consumer Marketing, Vol.17, No.4, pp.322 - 337.

Ross, C., Orr, E.S., Sisic, M., Arseneault, J.M., Simmering, M.G., Orr, R.R. (2009). "Personality and Motivations Associated with Facebook Use". Computers in Human Behaviour, Vol.25, No.2, pp.578-586.

Seregina, A. (2011). "Fanaticism - Its Development and Meanings in Consumers' Lives Marketing". (Unpublished Master's Thesis). Aalto University

Smith, S., Fisher, D., Cole, S.J. (2007). "The Lived Meanings of Fanaticism: Understanding the Complex Role of Labels and Categories in Defining the Self in Consumer Culture". Consumption Markets \& Culture, Vol.10, No.2, pp.77-94.

Soto, C.J., John, O.P. (2009). "Ten Facet Scales for the Big Five Inventory: Convergence with NEO PI-R Facets, Self-Peer Agreement, and Discriminant Validity". Journal of Research in Personality, Vol.43, pp.84-90.

Steiner, C.J. (2004). “A Conceptual Framework for Studying Fanatical Managers". Management Decision, Vol.42, No.6, pp.738 - 757.

Tang, J.H., Chen, M.C., Yang, C.Y., Chung, T.Y., Lee, Y.A. (2016). "Personality Traits, Interpersonal Relationships, Online Social Support, and Facebook Addiction", Telematics and Informatics. Vol.33, No.1, pp. 102-108.

Thorne, S.L. (2003). "The Antecedents and Consequences of Consumer Fanaticism". (Unpublished Doctorate Thesis). Southern Illinois University: Carbondale.

Thorne, S., Bruner, G.C. (2006). "An Exploratory Investigation of the Characteristics of Consumer Fanaticism". Qualitative Market Research, Vol.9, No.1, pp.51-72.

Thorne, S. (2011). "An Exploratory Investigation of the Theorized Levels of Consumer Fanaticism". Qualitative Market Research: An International Journal, Vol.14, No.2, pp.160-173. 